\title{
Pengaruh Reward Terhadap Kinerja Pegawai Pada Kantor Pelayanan Pajak
}

\author{
${ }^{1}$ Henry Sg Naiboho, ${ }^{2}$ Syafri, ${ }^{3}$ Taufik Azhar, ${ }^{4}$ Deli Yanto \\ ${ }^{1-4}$ Program Magister Manajemen, Fakultas Ekonomi, Universitas Islam Sumatera Utara
}

\author{
Article history \\ Received: 18 Nov 2020 \\ Revised: 13 Dec 2020 \\ Accepted: 2 Jan 2021 \\ *Corresponding Author: \\ Henry Sg Naiboho, \\ Program Studi Magister \\ Manajemen, Fakultas \\ Ekonomi, Universitas \\ Islam Sumatera Utara \\ Email: \\ henrysgnaiboho@gmail.co \\ $\underline{\mathrm{m}}$
}

\begin{abstract}
Abstrak: Sumber Daya Manusia (SDM) memegang peranan penting dalam mencapai tujuan yang telah ditetapkan suatu organisasi, sehingga aka nada reward sebagai penghargaan atas hasil kerja mereka. Pada dasarnya rewards tidak jauh berbeda dengan kompensasi yang merupakan kontribusi yang diterima atas pekerjaan yang telah dikerjakan. Adapun masalah penelitian yaitu pengaruh rewards terhadap kinerja pegawai pada KPP Pratama Medan Polonia. Metode yang digunakan dalam penelitian dengan pendekatan survey melalui observasi, wawancara, pembagian kuesioner dan studi dokumentasi. Metode analisis data yang digunakan adalahanalisis regresi linier berganda. Populasi dalam penelitian ini adalah sebagian pegawai PT. Harapan Bersama Lestari Medan yang berjumlah 38 pegawai. Secara parsial hasil penelitian ini menunjukan bahwa Variabel reward memiliki nilai p-value (pada kolom Sig.) $0,001<0,05$ artinya signifikan, sedangkan t hitung 3,346> dari t tabel 1,990 artinya signifikan. Hal ini berarti bahwa reward berpengaruh terhadap kinerja pegawai.

Kata Kunci : Pengaruh, Reward, Kinerja, Pegawai, Pelayanan Pajak
\end{abstract}

\section{PENDAHULUAN}

Kinerja pegawai adalah salah satu aspek penting yang wajib diperhatikan oleh organisasi, karena kinerja pegawai menuntun organisasi untuk mencapai tujuannya. Peningkatan kinerja pegawai menjadi penting mengingat perubahan arah kebijakan pemerintah sebagaimana dikehendaki oleh semangat reformasi untuk lebih luas memberi ruang gerak dan peran serta yang lebih besar bagi masyarakat dalam kegiatan pemerintahan dan pembagunan dimana pemerintah beserta aparaturnya lebih berperan sebagai fasilitator. Adapun pemberian reward menjadi sebagai penghargaan atas hasil kerja mereka. Sesuatu tersebut wajar sebagai apresiasi, sebagai ungkapan terima kasih dan perhatian kita (Wijarnako, 2008). Pada dasarnya rewards tidak jauh berbeda dengan kompensasi yang merupakan kontribusi yang diterima atas pekerjaan yang telah dikerjakan. Program kompensasi penting bagi organisasi karena mencerminkan usaha organisasi untuk mempertahankan sebagai komponen utama dan merupakan komponen biaya yang paling penting.

Kata reward berasal dari bahasa inggris yang berarti ganjaran atau hadiah (Echolas dan Shadily, 2009). Jelaslah bahwa pemberian reward atau kompensasi merupakan salah satu cara meningkatkan kinerja pegawai yang pada akhirnya meningkatkan kinerja organisasi. Selanjutnya melalui rewards atau pemberian kompensasi juga diharapkan semangat dan kegairahan kerja pegawai akan bertambah sehingga kinerja yang tinggi akan tercapai. Apabila organisasi mampu meningkatkan semangat dan kegairahan kerja maka organisasi akan lebih mudah memperoleh keuntungan sehingga eksistensi eksistensi akan terjaga. Fokusnya adalah bagaimana usaha untuk selalu memperbaiki dan meningkatkan kinerja yang diindikasikan dalam bentuk kuantitas kerja, kualitas kerja, tata cara kerja dan dalam penyelesaian kerja sehari hari. 
Manajer mengevaluasi hasil kinerja individu baik secara formal maupun informal. Dengan kata lain, Reward adalah segala sesuatu yang berupa penghargaan yang menyenangkan perasaan yang diberikan kepada pegawai dengan tujuan agar pegawai tersebut senantiasa melakukan pekerjaan yang baik dan terpuji. Sehingga dengan reward, maka usaha menumbuhkan perasaan diterima dilingkungan kerja, yang menyentuh aspek kompensasi dan aspek hubungan antara para pekerja yang satu dengan yang lainnya (Nawawi, 2009). Dalam konsep manajemen, Reward merupakan salah satu alat untuk meningkatkan motivasi kinerja para pegawai. Metode ini bisa mengasosiasikan perbuatan dan kelakuan seseorang denga perasaan bahagia, senang dan biasanya akan membuat mereka melakukan suatu perbuatan baik secara berulang-ulang. Reward juga bertujuan agar seseorang menjadi semakin giat dalam usaha memperbaiki atau meningkatkan prestasi yang telah dicapainya.

Setiap pegawai dalam organisasi dituntut untuk memberikan kontribusi positif melalui kinerja yang baik, mengingat kinerja organisasi tergantung pada kinerja pegawainya (Gibson, et all, 2008). Kinerja adalah tingkat dimana para pegawai mencapai persyaratan pekerjaan secara efisien dan efektif (Simamora, 2010). Menurut Dessler (2008) kinerja pegawai merupakan prestasi kerja, yakni perbandingan antara hasil kerja yang dapat dilihat secara nyata dengan standard kerja yang telah ditetapkan organisasi. Kemudian Robbins (2008) mendefinisikan kinerja yaitu suatu hasil yang dicapai oleh pegawai dalam pekerjaanya menurut kriteria tertentu yang berlaku untuk suatu pekerjaan. Pertimbangan atas keberhasilan pekerjaan yang dilakukan karyawan tentu didasarkan pada beberapa aspek yang mendukungnya. Hal ini tidak terlepas dari suatu pengembangan yang dilakukan organisasi secara berkesinambungan.

\section{METODOLOGI PENELITIAN}

Metode pengumpulan data yang digunakan dalam penelitian dengan pendekatan survey melalui observasi, wawancara, pembagian kuesioner dan studi dokumentasi. Metode analisis data yang digunakan adalahanalisis regresi linier berganda. Adapun lokasi penelitian ini dilakukan di Kantor Pelayanan Pajak Pratama Medan Polonia Jalan Sukamulia No. 17A Medan. Populasi dalam penelitian ini adalah seluruh Pegawai Kantor Pelayanan Pajak Pratama Medan Polonia yang berjumlah sebanyak 84 orang. Seluruh populasi dijadikan sampel penelitian akan tetapi Kepala Kantor tidak mengisi kuesioner sehingga sampel penelitian 83 orang.

\section{Variabel Penelitian}

1. Variabel terikat (Dependent Variable).

Variabel terikat adalah variabel yang dipengaruhi oleh variabel bebas yang sifatnya tidak dapat berdiri sendiri serta menjadi perhatian utama peneliti. Dalam penelitian ini yang menjadi variabel terikat adalah Kinerja Pegawai $(Y)$.

2. Variabel bebas (Independent Variable).

Variabel bebas yaitu variabel yang mempengaruhi variabel terikat, baik itu secara positif atau negatif, serta sifatnya dapat berdiri sendiri. Dalam penelitian ini yang menjadi variabel bebas Reward $\left(\mathrm{X}_{1}\right)$.

\section{Sumber dan Cara Penemuan Data}


1. Sumber Data Primer

Yaitu sumber data yang diperoleh pertama kali dan merupakan segala informasi yang diperoleh dari responden baik melalui kuesioner observasi yang dicatat oleh peneliti secara langsung dari objek penelitian.

2. Sumber Data Sekunder

Yaitu sumber data yang diperoleh secara tidak langsung pada objek penelitian yang dapat berupa dokumen, buku, catatan, laporan, arsip, monografi dan lain-lain terutama yang berkaitan dengan masalah penelitian.

\section{Validitas}

Teknik untuk mengukur validitas kuesioner adalah dengan menghitung korelasi antar data pada masing-masing pernyataan dengan skor total, memakai rumus korelasi product moment, sebagai berikut :

$$
r=\frac{n\left(\sum X Y\right)-\sum X \sum Y}{\sqrt{\left[n X^{2}-\left(\sum X\right)^{2}\right]\left[n \sum Y^{2}-\left(\sum Y\right)^{2}\right]}}
$$

Item Instrumen dianggap Valid jika Jika $r$ hitung $>\mathrm{r}$ tabel..

\section{Reliabilitas}

Uji reliabilitas berguna untuk menetapkan apakah instrumen yang dalam hal ini kuesioner dapat digunakan lebih dari satu kali, paling tidak oleh responden yang sama akan menghasilkan data yang konsisten. Dengan kata lain, reliabilitas instrumen mencirikan tingkat konsistensi. Banyak rumus yang dapat digunakan untuk mengukur reliabilitas diantaranya adalah rumus Spearman Brown

$$
r_{11}=\frac{2 \cdot r b}{1+r b}
$$

Ket :

$\mathrm{r}_{11}$ adalah nilai reliabilitas

$\mathrm{r}_{\mathrm{b}}$ adalah nilai koefisien korelasi

Item pertanyaan dianggap reliable jika Nilai Koefisien Reliabilitas lebih besar dari 0,6.

\section{Teknik Analisis Data}

1. Uji Multikolinieritas

2. Uji Heteroskedasitistas

3. Uji Autokorelasi

4. Uji Regresi

Setelah data diperoleh, selanjutnya data dianalisis dengan menggunakan Metode Ordinary Least Square (OLS) dengan bentuk / model persamaan sebagai berikut :

$$
\mathrm{Y}=\mathrm{b}_{0}+\mathrm{b}_{1} \mathrm{x}_{1}+\mathrm{b}_{2} \mathrm{x}_{2}+\mathrm{b}_{2} \mathrm{x}_{2}
$$

Keterangan :

$\mathrm{Y} \quad=$ Kinerja Pegawai (dependent variable)

$\mathrm{x}_{1} \quad=$ Motivasi $\mathrm{n}$ (Independent variable)

$\mathrm{x}_{2} \quad=$ Reward (Independent variable) 
$x_{3}=$ Gaya Kepemimpinan (Independent variable)

$\mathrm{b}_{1} \mathrm{~b}_{2}, \mathrm{~b}_{3}=$ Koefiesien regresi berganda (multiple regression)

\section{Uji Parsial (Uji t)}

Uji Parsial dilakukan untuk mengetahui pengaruh masing-masing variabel bebas terhadap variabel terikat.

$$
\mathbf{t}=\frac{b}{S_{b}}
$$

Kriteria pengujian dilakukan dengan membandingkan nilai t-hitung dengan t-tabel yaitu :

1. Jika t-hitung $>\mathrm{t}$-tabel, tolak $\mathrm{H}_{\mathrm{o}}$ terima $\mathrm{H}_{\mathrm{a}}$ pada taraf signifikan $95 \%$

2. Jika t- hitung < t-tabel, Terima $\mathrm{H}_{\mathrm{o}}$ tolak $\mathrm{H}_{\mathrm{a}}$ pada taraf signifikan $95 \%$

\section{Uji Simultan (Uji F)}

Uji ini dilakukan untuk mengetahui pengaruh variabel bebas terhadap variabel terikat secara serempak (simultan). Adapun kriteria pengujian dilakukan dengan membandingkan F-hitung dengan F-tabel, sebagai berikut :

1) Bila $F_{\text {hitung }} \geq \mathrm{F}_{\text {tabel }}$ pada taraf signifikan $95 \%$, maka hipotesis diterima

2) Bila $\mathrm{F}_{\text {hitung }} \leq \mathrm{F}_{\text {tabel }}$ pada taraf signifikan $95 \%$, maka hipotesis ditolak

\section{Uji Determinasi $\left(\mathbf{R}^{2}\right)$}

Uji ini dilakukan untuk mengetahui seberapa besar persentase variabel Gaya Kepemimpinan dan Motivasi Kerja mampu menerangkan variabel Kinerja Pegawai. Uji ini dapat dilihat dengan menggunakan rumus determinan sebagai berikut :

$$
\begin{aligned}
& \mathrm{D}=\mathrm{R}^{2} \times 100 \% \\
& \mathrm{D}=\text { Determinasi } \\
& \mathrm{R}^{2}=\text { Koefisien Determinasi }
\end{aligned}
$$

\begin{tabular}{|c|c|c|c|c|c|c|}
\hline \multirow{2}{*}{ Instrumen } & \multicolumn{6}{|c|}{ Frekwensi (Persentase) } \\
\hline & 5 & 4 & 3 & 2 & $\mathbf{1}$ & Total \\
\hline 1. KP1 & 33,7 & 48,2 & 18,1 & 0 & 0 & 100 \\
\hline 2. $\mathrm{KP} 2$ & 24,1 & 68,7 & 3,6 & 2,4 & 1,2 & 100 \\
\hline 3. KP3 & 18,1 & 61,4 & 19,3 & 1,2 & 0 & 100 \\
\hline 4. KP4 & 26,5 & 68,7 & 4,8 & 0 & 0 & 100 \\
\hline 5. KP5 & 30,1 & 59,0 & 8,4 & 1,2 & 1,2 & 100 \\
\hline 6. KP6 & 18,1 & 60,2 & 20,5 & 1,2 & 0 & 100 \\
\hline 7. KP7 & 39,8 & 60,2 & 0 & 0 & 0 & 100 \\
\hline 8. KP8 & 37,3 & 50,6 & 12,0 & 0 & 0 & 100 \\
\hline 9. KP9 & 51,8 & 38,6 & 6,0 & 3,6 & 0 & 100 \\
\hline
\end{tabular}

\section{HASIL DAN PEMBAHASAN}

\section{Statistik Deskriptif}

Tabel 1. Statistik Deskriptif 


\begin{tabular}{lcccccc}
\hline 10. KP10 & 39,8 & 55,4 & 3,6 & 1,2 & 0 & 100 \\
\hline 1. R1 & 38,6 & 61,4 & 0 & 0 & 0 & 100 \\
2. R2 & 30,1 & 67,5 & 2,4 & 0 & 0 & 100 \\
3. R3 & 19,3 & 61,4 & 18,1 & 1,2 & 0 & 100 \\
4. R4 & 37,3 & 62,7 & 0 & 0 & 0 & 100 \\
5. R5 & 22,9 & 74,7 & 2,4 & 0 & 0 & 100 \\
6. R6 & 32,5 & 59,0 & 8,4 & 0 & 0 & 100 \\
7. R7 & 24,1 & 65,1 & 10,8 & 0 & 0 & 100 \\
8. R8 & 37,3 & 61,4 & 1,2 & 0 & 0 & 100 \\
9. R9 & 25,3 & 67,5 & 7,2 & 0 & 0 & 100 \\
10.R10 & 32,5 & 56,6 & 10,8 & 0 & 0 & 100 \\
\hline
\end{tabular}

\section{Uji Kualitas Data}

Tabel 2. Uji Validitas Variabel

\begin{tabular}{llccc}
\hline \multicolumn{2}{l}{ Instrumen } & r-hitung & r-tabel & Keterangan \\
\hline 1) & R1 & 0.555 & 0.215 & Valid \\
2) & R2 & 0.569 & 0.215 & Valid \\
3) & R3 & 0.584 & 0.215 & Valid \\
4) & R4 & 0.510 & 0.215 & Valid \\
5) & R5 & 0.437 & 0.215 & Valid \\
6) & R6 & 0.451 & 0.215 & Valid \\
7) & R7 & 0.444 & 0.215 & Valid \\
8) & R8 & 0.558 & 0.215 & Valid \\
9) & R9 & 0.532 & 0.215 & Valid \\
10) & R10 & 0.644 & 0.215 & Valid \\
\hline 1) & KP1 & 0.651 & 0.215 & Valid \\
2) & KP2 & 0.354 & 0.215 & Valid \\
3) & KP3 & 0.624 & 0.215 & Valid \\
4) & KP4 & 0.629 & 0.215 & Valid \\
5) & KP5 & 0.610 & 0.215 & Valid \\
6) & KP6 & 0.696 & 0.215 & Valid \\
7) & KP7 & 0.694 & 0.215 & Valid \\
8) & KP8 & 0.543 & 0.215 & Valid \\
9) & KP9 & 0.645 & 0.215 & Valid \\
10) & KP10 & 0.589 & 0.215 & Valid \\
\hline
\end{tabular}




\section{Reliabilitas}

Tabel 3. Uji Reliabilitas Variabel

\begin{tabular}{lccc}
\hline \multicolumn{1}{c}{ Variabel } & $\begin{array}{c}\text { Cronbach's } \\
\text { Alpha }\end{array}$ & $\begin{array}{c}\text { Batas } \\
\text { Reliabilitas }\end{array}$ & Keterangan \\
\hline Reward (X2) & 0.726 & 0.6 & Reliabel \\
Efektivitas Kerja & 0.748 & 0.6 & Reliabel \\
Pegawai (Y) & & 0.6 & Reliabel \\
& & 0.6 & Reliabel \\
\hline
\end{tabular}

Dari data tabel 3 di atas dapat dilihat bahwa hasil perhitungan uji reliabilitas menunjukkan alpha cronbach's pada masing-masing kolom variabel tersebut lebih besar dari 0,6 (batas reliabilitas) maka dapat dinyatakan instrumen tersebut reliabel.

\section{Pengujian Hipotesis}

\section{Pengujian Hipotesis dengan Uji t}

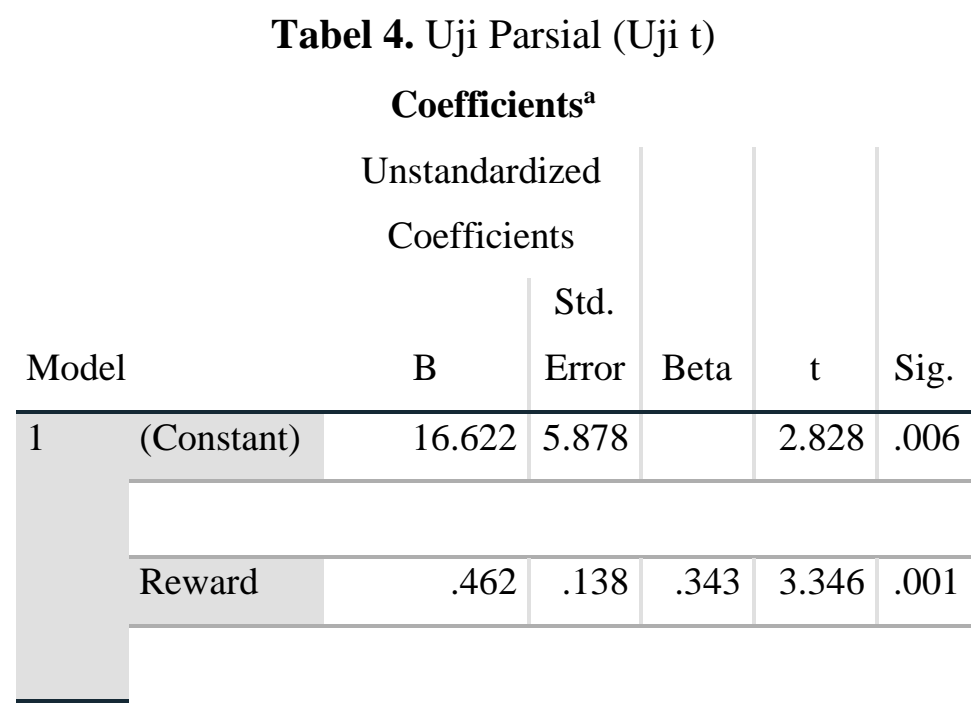

Berdasarkan tabel di atas, diketahui nilai $t$ hitung dari masing-masing variabel independen secara parsial berpengaruh terhadap variabel dependen yaitu Variabel reward memiliki nilai $p$-value (pada kolom Sig.) 0,001 < 0,05 artinya signifikan, sedangkan t hitung 3,346 > dari t tabel 1,990 artinya signifikan. Hal ini berarti bahwa reward berpengaruh terhadap kinerja pegawai.

\section{Analisis Koefisien Determinasi $\left(\boldsymbol{R}^{2}\right)$}

Tabel 5. Hasil Analisis Koefisien Determinasi

\section{Model Summary}

\begin{tabular}{ll|r|r|r} 
Model & R & R Square & R Square & $\begin{array}{l}\text { Adjusted } \\
\text { the Estimate }\end{array}$ \\
\hline 1 & $.681^{\mathrm{a}}$ & .464 & .443 & 2.902 \\
\hline
\end{tabular}


Hasil olahan pada tabel di atas terlihat nilai koefisien determinasi $\left(R^{2}\right)$ yang sudah disesuaikan (Adjusted $R$ Square) sebesar 0,443. Artinya 44,3\% variabel dependen (kinerja pegawai) dipengaruhi atau dijelaskan oleh variabel independen yaitu reward dan sisanya sebesar 54,7\% (100\% - 44,3\%) dipengaruhi atau dijelaskan oleh variabel lain di luar variabel yang digunakan dalam penelitian ini.

\section{Hasil Persamaan Regresi}

Tabel 6. Uji Regresi Linier Berganda

\section{Coefficients $^{\mathrm{a}}$}

\begin{tabular}{|c|c|c|c|c|c|c|}
\hline \multirow[b]{2}{*}{ Model } & \multicolumn{3}{|c|}{$\begin{array}{c}\text { Unstandardized } \\
\text { Coefficients }\end{array}$} & \multirow[b]{2}{*}{ Beta } & \multirow[b]{2}{*}{$\mathrm{t}$} & \multirow[b]{2}{*}{ Sig. } \\
\hline & & B & Std. Error & & & \\
\hline \multirow[t]{2}{*}{1} & (Constant) & 16.622 & 5.878 & & 2.828 & .006 \\
\hline & Reward & .462 & .138 & .343 & 3.346 & .001 \\
\hline
\end{tabular}

Nilai besaran koefisien regresi $\beta_{2}$ sebesar 0,462 pada penelitian ini dapat diartikan bahwa variabel reward (X2) berpengaruh terhadap efektivitas kerja pegawai (Y). Hal ini menunjukkan bahwa ketika variabel reward terpenuhi, maka kinerja pegawai akan naik 0,462 satuan.

\section{Pengaruh Reward Terhadap Kinerja Pegawai}

Secara parsial hasil penelitian ini menunjukan bahwa reward berpengaruh positif dan signifikan terhadap kinerja pegawai di Kantor Pelayanan Pajak Pratama Medan Polonia. Pengaruh positif menunjukkan bahwa pengaruh reward adalah searah dengan kinerja pegawai atau dengan kata lain adanya reward yang baik akan berpengaruh terhadap kinerja pegawai yang baik/tinggi, demikian sebaliknya bila reward yang baik tersebut tidak terpenuhi, maka kinerja pegawai akan rendah/buruk. Pengaruh signifikan menunjukkan bahwa reward mempunyai peranan yang penting dalam meningkatkan kinerja pegawai di Kantor Pelayanan Pajak Pratama Medan Polonia.

Hal ini terbukti dari jawaban responden yang rata-rata setuju bahwa anda berupaya agar hasil kerja anda lebih baik, pegawai mengharapkan penghargaan jika anda memiliki prestasi kerja yang tinggi, pemberian Gaji diberikan dengan lancer, pimpinan memberikan penghargaan kepada pegawai yang memiliki prestasi kerja yang tinggi, pimpinan sering menyarankan pegawai agar memiliki prestasi kerja yang tinggi, penghargaan yang diberikan kepada pegawai dapat menambah semangat kerja pegawai, semangat kerja pegawai yang tinggi berpengaruh terhadap kinerja, pegawai mendapat bonus /uan lembur jika bekerja lembur, diberikannya penghargaan terhadap pegawai yang berprestasi menjadi suatu kebanggan bagi pegawai, pegawai yang memperoleh penghargaan akan semakin termotivasi untuk bekerja lebh baik.

\section{KESIMPULAN}

Sesuai hasil analisis penelitian maka dapat diambil kesimpulan sesuai tujuan penelitian yang dikemukakan: 
1. Reward berpengaruh positif dan signifikan terhadap kinerja pegawai Kantor Pelayanan Pajak Pratama Medan Polonia, hal ini didukung analisis thitung > ttabel $(3,346>2,009)$ pada $\mathrm{n}=83$ pada taraf sifgnifikansi $95 \%$.

2. Nilai F-hitung > F tabel $(22,772>2,72)$ hal ini menyatakan bahwa secara bersama-sama (multiple) terdapat pengaruh positif dan signifikan reward terhadap kinerja pegawai Kantor Pelayanan Pajak Pratama Medan Polonia. Dengan demikian hipotesis yang diajukan diterima kebenarannya.

\section{DAFTAR PUSTAKA}

Dessler, G. 2008. Human Resource Management. 11th Edition, New Jersey: Pearson Education.

Echolas John M. \& Hasan, Shadily. 2009. Kamus Inggris Indonesia. Jakarta: Gramedia.

Gibson \& Ivancevich \& Donnely. 2008. Organisasi dan manajemen. Perilaku, struktur, proses. Edisi keempat. Jakarta: Erlangga.

Nawawi. 2009. Metode Penelitian Bidang Sosial. Jogjakarta: Gajah Mada, University Press

Robbins, Stephen P. 2008. Perilaku Organisasi. Jakarta: PT. Indeks

Simamora Henry. 2010. Manajemen Pemasaran Internasional, Edisi Pertama. Jakarta: Salemba Empat

Wijarnako. 2008. Teori dan Proses Kebijakan Publik. Yogyakarta: Media Presindo 